\title{
Which Is More Challenging? To Be An Alzheimer's Patient, Or To Be A Caregiver For One?
}

\begin{abstract}
Background: The behavioral and psychological symptoms of Alzheimer's disease impose a significant burden on the patient's family and caregiver.

Objectives: The purpose of this study was to assess the health of individuals who care for Alzheimer's patients by using the World Health Organization Quality of Life Questionnaire (WHOQoL-Bref) and the Caregiver Stress Scale, and also to evaluate the relationship between the health and demographic data of these caregivers.

Methods: The study was conducted with 55 participants providing care to Alzheimer's patients who were admitted to Neurology Polyclinic, and with 55 healthy control groups with age and demographic characteristics similar to that of the caregivers. The form distributed to the participating caregivers included questions relating to socio-demographic characteristics, patient information, the caregiver's current health, and the Caregiver Stress Scale. The WHOQoL-Bref questionnaire was also administered to each participant to assess their quality of life.
\end{abstract}

Results: Compared to the control group, caregivers had statistically significantly lower scores in all domains (Physical Health, Psychological Health, Social Relationships, Environmental Health) of the WHOQoL-Bref questionnaire $(p=0.000)$. The mean stress index of the caregivers was 7.31 \pm 3.31 . A negative correlation was identified between the stress index score and the domain scores of the WHOQoL-Bref questionnaire.

Conclusion: The disease especially affects the caregivers of Alzheimer's patients, leading to an increase in their stress index, and to a decrease in their quality of life. When treating Alzheimer's patients, it is important to also consider their caregivers, to inform them about Alzheimer's disease, and to even provide treatment for them when needed.

Key Words: Al zheimer Disease; Caregivers; Dementia; Quality of Life; Stress Psychological

\section{Council for Innovative Research}

Peer Review Research Publishing System

\section{Journal: Journal of Social Sciences Research}

\author{
Vol. 8, No. 3 \\ jssreditor.cir@gmail.com
}

www.jssronline.com 


\section{Introduction}

Is it more challenging to be an Alzheimer's patient, or to care for one? In the initial stages of Alzheimer's disease patients begin to experience memory loss and changes in personality. They might experience difficulties in remembering recent events, in recognizing people they know, or in recalling the name of objects. However, patients at this early stage of the disease generally do not require external care or assistance. In the mid-stages of the disease, patients begin to experience delusions, significant changes in personality, denial of memory impaiment, and significant impaiment of occupational activity. At this stage, patients become increasingly dependent on external care. In the advanced stages of the disease, when patients become unable to perform daily activities of their own, and begin to develop motor skill impaiment along with urine and fecal incontinence, thus, external care becomes obligatory ${ }^{[1]}$.

Advances in the treatment of Alzheimer's diseases, the medical care provided in Neurology Polyclinics and the increase in the ratio of patients seeking treatment has considerably lengthened the average lifespan of Alzheimer's patients. The 2010 World Alzheimer Report estimates 35.6 million patients across the world with dementia, and that this number will reach 65.7 million in 2030 , and 115.4 million in $2050^{[2]}$. In addition to these developments; industrialization, adaption to urban life and economic concerns are leading most family members to work actively, which reduces the number of individuals at home who might provide care to patients. Those who can remain at home are generally the patient's spouse, children, and daughters-in-law, who assume the role of caregivers either willingly or unwillingly. In Turkey, care for Alzheimer's patients is generally given at home, although nursing homes for the elderly and those in need of constant care have also appeared in recent years. In addition to the known symptoms of Alzheimer's patients, the problems experienced by caregivers have also begun to attract attention in recent years. Factors that affect the caregiver burden includes the caregiver's age, gender, relation with the patient, education level, economic status, and accompanying physical and mental diseases ${ }^{[3]}$.

In this study, the caregiver burden and health of those taking care of Alzheimer's patients were evaluated by using the Caregiver Stress Scale and the WHOQoL-Bref questionnaire, and comparisons were made between the scores for these questionnaires and the caregivers' demographic data.

\section{Methods}

This study was designed as a prospective study. The study was conducted with the caregivers of Alzheimer's patients who were admitted to the Neurology Polyclinic between January 2013 and July 2013. An Ethics Committee approval was obtained for the study (Number: B.30.2.HRÜ.0.20.05.00.050.01.04-166). The aim was to include mainly those who care for the patients at home rather than those accompanying the patients for their clinic visits. The address and telephone numbers of these caregivers were recorded. All participants were informed regarding the purpose of the study, and written informed consents were obtained from each one of them. Information regarding factors that affect the caregiver burden, such as the caregiver's age, gender, relation to the patient, education level, economic status, and accompanying physical and mental diseases were recorded. Information on the duration of the disease and any other concurrent diseases were also recorded. Questions from the WHOQoL-Bref Questionnaire and Caregiver's Stress Index were read to the participants one-by-one. The questions were further clarified to the participants whenever necessary, and their answers were recorded. Assistance was provided to illiterate participants for facilitating the completion of the questionnaire forms. The relevant tests were administered to 26 of the participants with the same method. However, it was not possible to gather all 55 caregivers at the same place and time to complete the study forms. Among the study participants, 12 were not available to meet during working hours; these participants were therefore invited to the Neurology service at a later data that was suitable for them, and the forms were completed during their eventual visit. For 17 of the study participants, the study forms were applied on the same day the patient was diagnosed with Alzheimer's disease, and immediately after the relative to assumed the role of the patient's caregiver was detemined. The control group was selected among healthy individuals admitted to the Neurology Polyclinic who shared similar age and demographic characteristics as the study group, but lacked any history of previous psychiatric diseases, and had no patient or elderly person to whom they provided care. The forms for the control group were performed in the Patients' Rights unit of the hospital.

Potential participants who had a history of psychiatric disease prior to becoming a caregiver were excluded from the study. Individuals in the control group who had psychiatric diseases were also excluded from the study. Thus, three individuals from the study group and five individuals from the control group (for a total of eight individuals) were excluded from the study due to a history of prior psychiatric diseases. Based on the study exclusion criteria, a total of 55 participants were included in the study group, while 55 participants with age and demographic characteristics similar to the study group were included in the control group. Written informed consent foms containing information regarding the study purpose were provided to the participants in both the study group and the control group for their reading. Signed informed consent forms were then obtained from each participant.

\section{Data Collection Tools}

In this study, the Participant Form (used to record the socio-demographic characteristics of the participants), the WHOQoL-Bref questionnaire, and the Caregiver Stress Index were used as data collection tools.

The WHOQoL-Bref questionnaire is a shorter version of the WHOQoL-100 questionnaire. It was designed by including one question from each one of the 24 sections constituting the WHOQoL-100 questionnaire, and two questions regarding general health and quality of life. The WHOQoL-100 is scored in four "domains," which are: (i) Physical health, (ii) 
Psychological Health, (iii) Social Relationships, and (iv) Environmental Health. WHOQoL-Bref also consists of four domains ${ }^{[4]}$.

The Caregiver's Stress Index is used to determine the stress levels of the caregivers based on cognitive status and problematic behaviors of the patients and provides support for guiding roles and activities of the caregivers.

Factors such as family conflicts, caregiver and working life interference, social support for caregiving, and experience as caregiver are among the factors that influence the Index score. The Index consists of 13 questions, rated as 0 - 1. A "yes" answer for each area of the Index indicates the caregiver's need for support in that particular area. A total score of seven or greater indicated as high level of caregiver stress ${ }^{[5]}$.

\section{Statistical Analysis}

An analysis of study data was performed on a computer using the SPSS (Statistical Program for Social Sciences) 11.5 statistical package program. During the data analysis, the chi-square test, the independent samples $t$-test, and Speaman's correlation analys is were administered.

\section{Results}

The study was conducted with a study group consis ting of 55 caregivers taking care of Alzheimer's patients, and a control group consisting of 55 healthy participants. Of the participants in both groups, $89.1 \%(n=98)$ were female, while $10.9 \%$ $(n=12)$ were male. In addition, $94.5 \%(n=104)$ of the participants were married, while $5.5 \%(n=6)$ were single. The age average of participants in both groups was $48.61 \pm 13.05$ years. For the WHOQoL-Bref questionnaire, the average scores for the Physical Health, Psychological Health, Social Relationships, and Environmental Health domains were 69.31 \pm 22.29 , $66.88 \pm 22.92,66.65 \pm 23.55$, and $70.43 \pm 20.16$, respectively. Among participants in both groups, $7(12.7 \%)$ were illiterate, 34 $(61.8 \%)$ were elementary school graduates, 11 (20\%) were high school graduates, and $3(5.5 \%)$ were university graduates.

Within the study group, $49(89.1 \%)$ of the caregivers were female, while $6(10.9 \%)$ were male. No statistically significant difference was identified between the gender of the caregivers and the WHOQoL-Bref scores $(p>0.005)$. The average age in the study group was $47.98 \pm 13.65$ years. Furthemore, $90.9 \%(n=50)$ of the caregivers were married, while $9.1 \%(n=5)$ were single. No statistically significant difference was identified between the marital status of the caregivers and the WHOQoL-Bref scores ( $p>0.005)$. With respect to education level, $7(12.7 \%)$ of the caregivers were illiterate, $34(61.8 \%)$ were elementary school graduates, $11(20 \%)$ were high school graduates, and $3(5.5 \%)$ were university graduates. No statistically significant difference was identified between the education level of the caregivers and the WHOQoL-Bref scores $(p>0.005)$. The average score for the Physical Health, Psychological Health, Social Relationships, and Environmental Health domains were $58.81 \pm 19.46,56.47 \pm 18.08,52.72 \pm 21.37$, and $56.60 \pm 15.83$, respectively. With respect to relationship with the patient, $14.5 \%(n=8)$ of the caregivers were the patient's spouse, $43.6 \%(n=24)$ were the patient's child, and $41.8 \%(n=23)$ were the patient's daughter-in-law. No statistically significant difference was identified between the caregiver's relations hip with the patient and the WHOQoL-Bref scores $(p>0.005)$. Correlation analyses were performed in order to determine whether any correlation existed between the duration of care and the caregiver quality of life. These analyses revealed no correlation between the duration of care and the domains for the quality of life score $(p>0.005)$. Among the Alzheimer's patients, $72 \%$ had concurrent diagnosed conditions. Among these conditions, hypertension ranked first with a ratio of $43 \%$, followed by diabetes mellitus and other diseases with a ratio of $16 \%$. It was also determined that $86 \%$ of the Alzheimer's patients were on regular medication. No statistically significant difference was identified between the concurrent diseases of the Alzheimer's patients and the WHOQoL-Bref scores of the caregivers. In addition, $14.5 \%$ of the caregivers had a history of sys temic disease. Four of the caregivers had hypertension, two had diabetes mellitus, and one had rheumatoid arthritis. No statistically significant difference was identified between the existing diseases of the caregivers and the WHOQoL-Bref scores $(p>0.005)$. An increase in the caregiver's age was associated with a decrease in the Physical Health subgroup domain scores of the Quality of Life questionnaire. The scores for the Physical Health domain were statistically significantly higher among the patients' spouse than among the patients' children and daughters in-law $(p<0.005)$. As many of the participating caregivers did not answer questions relating to monthly income, no statistical analys is could be performed with respect to income levels.

Within the control group, 46 (83.6\%) of the participants were female, while 9 (16.3\%) were male. The age average in the control group was $49.23 \pm 12.51$ years. Furthermore, one $(1.8 \%)$ of the participants in the control group was single, while 54 $(98.2 \%)$ were married. Among the participants of the control group, 49 (89.1\%) were elementary school graduates, 3 $(5.5 \%)$ were high school graduates, and $3(5.5 \%)$ were university graduates. In the WHOQoL-Bref questionnaire, the average scores for the Physical Health, Psychological Health, Social Relationships, and Environmental Health domains were $79.81 \pm 19.99,77.29 \pm 22.64,80.58 \pm 16.35$, and84.27 \pm 13.42 , respectively.

The mean stress index of the caregivers was 7.31 \pm 3.31 . A negative correlation was identified between the stress index score and the subscale scores of the WHOQoL-Bref questionnaire. Compared to the control group, caregivers had statistically significantly lower scores in all domains (Physical Health, Psychological Health, Social Relationships, and Environmental Health) of the WHOQoL-Bref questionnaire $(p=0.000)($ Table 1$)$.

\section{Discussion}

Taking care of a patient for extended periods of time can have detrimental effects on the caregiver, both mentally and physically. A person often becomes a caregiver due to unplanned circumstances, and the role is generally assumed 
unwillingly. For this reason, many people find themselves suddenly obliged to assume this role after one of their relatives becomes affected with a serious disease or condition ${ }^{[6]}$. Independent of language, country or culture, being a caregiver has become an integral part of life for millions of people across the world ${ }^{[7]}$. In fact, the care provided by family members forms the basis of caregiving activities in many countries. In other words, in many countries, care for the elderly and for those with diseases that require constant care is mainly provided not by health institutions, but by family members and close relatives. In a study conducted by Del Pino et al., it was observed that cultural differences affected the caregiver burden for nearly $29 \%$ of caregivers ${ }^{[8]}$. In the present study, the caregivers were all family members of the Alzheimer's patients.

The relatives of an Alzheimer's patient can be affected to varying degrees depending on the disease's stage of diagnosis When Alzheimer's disease is diagnosed at a relatively early stage, there is sufficient time to plan and determine the individuals who will take care of the patient. However, regardless of the stage of diagnosis, it is very likely for all members of the family to be affected by the difficulties associated with the care and requirements of an Alzheimer's patient. The role of caregiver for Alzheimer's patients is usually assumed by the patient's spouse, or other female members of the family $[9,10]$. Stone et al. previously detemined that $23 \%$ of all caregivers are the female spouses of the patients, while $13 \%$ are the male spouses of the patients ${ }^{[11]}$. In a multi-centered study with 1497 cases conducted by Reed et al., it was determined that the majority of caregivers were the patients' spouses. Reed et al. also determined that the children of Alzheimer's patients are adversely affected to a greater extent when assuming the role of caregiver than the patients' spouses, even when they become caregivers for a relatively shorter period of time ${ }^{[12]}$. Certain studies suggest that patients' children are affected to a greater extent when they become caregivers ${ }^{[13,14]}$, while other studies suggest that patients' spouses are affected to a greater extent ${ }^{[15,16]}$. The study of Hong et al. determined that caregiver spouses are adversely affected to a greater extent than caregiver children and daughters-in-law ${ }^{[17]}$. In the present study, the large majority of the caregivers (89.1\%) were female. In addition, $14.5 \%$ of the caregivers had a history of systemic dis ease. An increase in the caregiver's age was associated with a decrease in the Physical Health domain subgroup scores of the Quality of Life questionnaire. The scores for the Physical Health domain were statistically significantly higher among the patients' spouse than among the patients' children and daughters-in-law $(p<0.005)$. These findings were considered to be associated with the relatively more advanced age of the patients' spouses compared to the other caregiver groups, which increased the caregiver spouses' chance of displaying systemic diseases. No statistically significant difference was identified between the existing diseases of the caregivers and the WHOQoL-Bref scores ( $p>0.005)$. In addition, no statistically significant difference was identified between the Caregiver Stress Index scores and the WHOQoL-Bref scores $(p>0.005)$. The differences between the findings of the current study and other studies might be due to the differences that exist in the cultural aspects associated with the caregiver role between different countries. In fact, such differences might even be observed between different regions within the same country.

Alzheimer's diseases is often called a "family disease," since caregivers within a family are potential secondary patients themselves, who might develop complications in association with their caregiver role ${ }^{[18]}$. Despite of all difficulties they might encounter, caregivers are socially expected to devote themselves tirelessly to the care of the patient. Having to conduct and manage their occupational and family life while also being required to act as a caregiver can result in tremendous strain for many individuals. While handling all of these responsibilities at the same time, individuals might have difficulties in allocating and spending time for themselves. However, any expression by a caregiver of the problems and strains he/she experiences might be perceived by others as a rejection of the caregiver role. Caregivers may thus find themselves unable to manage the effects and strains engendered by the caregiver role. This, in tum, may lead to feelings of helplessness, guilt, anger, fear, and social isolation. In congruence with their cultural values, they tend to consider taking care of their loved ones as a duty, and might even refuse any outside help ${ }^{[19]}$. For these reasons, the stress levels of individuals taking care of Alzheimer's patients were very high in the currentstudy, as well ${ }^{[20,21]}$. In the present study, no statistically significant difference was identified between the duration of the disease and the Caregiver Stress Index. This finding might be explained with the adaptation shown by caregivers in the times following the initial diagnosis, and with the reduction or elimination of the patient's behavioral symptoms as a result of treatment. These two factors might have contributed to reducing the effect of disease duration on the caregivers' stress scores. A negative correlation was identified between the stress index score and the dimension scores for the WHOQoL-Bref questionnaire. In other words, an increase in the stress levels of the caregivers was associated with a negative effect on the quality of life. This might stem from the caregivers' lack of knowledge on how to cope with the disease and the patient, and the caregivers' inability or unwillingness to receive assistance.

As those taking care of Alzheimer's patients are deeply involved with work, family and the care of the patient at the same time, they generally tend to neglect their own physical and emotional health. The mental and physical health of the caregiver affects not only the quality of life of the caregiver him/herself, but also the quality of life of the patient. Many caregivers around the world - especially those who are not receiving adequate support - begin to experience considerable difficulties and adverse effects over time. In a previous study, $60.6 \%$ of caregivers expressed that they were unable to spend time for themselves, $78.8 \%$ expressed that they constantly felt tired, $84.9 \%$ expressed that they had difficulties communicating with the patient, and $56.9 \%$ expressed that they faced financial difficulties ${ }^{[22]}$. In a multicentered study conducted by Schulz et al., it was determined that the caregivers of Alzheimer's patients had very high stress levels, and that they exhibited a higher incidence of mood disorders, depression, insomnia, and lower quality of life scores [23]. In certain studies, the progression of the disease, as well as the additional behavioral problems (neuropsychiatric symptoms) this progression engenders, gradually increases the burden of the caregiver ${ }^{[10,23,24]}$ Neuropsychiatric symptoms are commonly observed during the course of Alzheimer's disease. Neuropsychiatric symptoms are the symptoms that have the greatest negative impact on the quality of life of both the patient and caregiver. 
In the present study, the quality of life scores of caregivers group were lower than those of the control group in all four subscales.

In conclusion, the gradual increase in the number of Alzheimer's patients, as well as the increase in the average human life span as a result of modern medicine, will lead to a parallel increase in the number of caregivers worldwide. This, in turn, will cause the medical needs of these caregivers themselves to become an important public health problem in many countries. Thus, it is necessary for physicians around the world that treat Alzheimer's disease to also investigate the mental and physical effects of the disease on caregivers, and to determine effective means and methods for supporting these caregivers.

\section{References}

1.Wimo A, Prince M. The World Alzheimer Report: The Global Economic Impact of Dementia. London: Alzheimer's Disease International; 2010.

2.Smith GC, Tobin SS, Robertson-Tchabo EA, Power PW. Strengthening Aging Families: Diversity in Practice and Policy. Thousand Oaks, CA: Sage Publications; 1995.

3.Mahoney R, Regan C, Katona C, Livingston G. Anxiety and depression in family caregivers of people with Alzheimer. disease-the LASER-AD study. Am J Geriatr Psychiatry.2005;13(9):795-801.

4.The WHOQOL Group. The World Health Organization Quality of Life Assessment (WHOQOL).Development and psychometric properties. Soc Sci Med.1998; 46(12):1569-85. doi:10.1016/S0277-9536(98)00009-4

5.Sullivan MT. Caregiver Strain Index (CSI). Home Healthc Nurse. 2003; 21 (3):197-198. PMID:12637827.ISSN: 0884$741 \mathrm{X}$.

6.Eicher PS, Batshaw ML. Cerebral palsy. Pediatr Clin North Am 1993; 40(3):537-551. PMID:8493064

7.Murat İlhan Atagün, Özlem Devrim Balaban, Zeliha Atagün, Mine Elagöz, Ayşegül Yılmaz Özpolat. Caregiver Burden in Chronic Diseases. Psikiyatride Güncel Yaklaşımlar-Current Approaches in Psychiatry 2011; 3(3):513-552. doi: 10.5455/cap.20110323

8.Del-Pino-Casado R, Millán-Cobo MD, Palomino-Moral PA, Frías-Osuna A. Cultural Correlates of Burden in Primary Caregivers of Older Relatives: A Cross-sectional Study. J Nurs Scholarsh. 2014 May;46(3):176-86. doi: 10.1111/jnu.12070.

9.Schulz R, Burgio L, Burns R, et al. Resources for Enhancing Alzheimer's Caregiver Health (REACH): overview, sitespecific outcomes, and future directions. Gerontologist 2003, 43(4):514-520. PMID:12937330

10.Salgado-García FI, Zuber JK, Graney MJ, Nichols LO, Martindale-Adams JL, Andrasik F. Smoking and Smoking Increase in Caregivers of Alzheimer's Patients. Gerontologist. 2013; 26. doi: 10.1093/geront/gnt149 .PMID:24371214

11.Burgener SC. Predicting quality of life in caregivers of Alzheimer's patients: the role of support from and involvement with the religious community. J Pastoral Care. 1999;53(4):433-446. PMID:11185294

12.Reed C, Belger M, Dell'agnello G, et al. Caregiver Burden in Alzheimer's Disease: Differential Associations in AdultChild and Spousal Caregivers in the GERAS Observational Study. Dement Geriatr Cogn. Disord. Extra 2014(4):51-64. DOI:10.1159/000358234

13. Hayslip B, Han G, Anderson CL: Predictors of Alzheimer's disease caregiving depression and burden: what noncaregiving adults can learn from active caregivers. Educ Gerontol 2008; 34(11): 945969.DOl: http://d x.doi.org/10.1080/03601270802016481.

14.Coen RF, O'Boyle CA, Coakley D, Lawlor BA: Individual quality of life factors distinquishing low -burden and highburden caregivers of dementia patients. Dement Geriatr Cogn Disord 2002; 13: 164-170. DOI:10.1159/000048648.

15.Germain S, Adam S, Olivier C, et al. Does cognitive impaiment influence burden in caregivers of patients with Alzheimer's disease? J Al zheimers Dis 2009; 17(1): 105-114. doi: 10.3233/JAD-2009-1016.

16.Andrén S, Elmståhl S. The relationship between caregiver burden, caregivers' perceived health and their sense of coherence in caring for elders with dementia. J Clin Nurs 2008; 17 (6): 790-799. doi: 10.1111/j.1365-2702.2007.02066.X.

17. Hong GR, Kim H. Family caregiver burden by relationship to care recipient with dementia in Korea. Geriatr Nurs 2008; 29(4): 267-274. doi: 10.1016/j.gerinurse.2007.09.004.

18.Andren S, Elmstahl S. The relationship between caregiver burden, caregivers' perceived health and their sense of coherence in caring for elders with dementia. J Clin Nurs 2008; 17 (6): 790-799. doi: 10.1111/j.1365-2702.2007.02066.X.

19.Brodaty H, Thoms on C, Thompson C, Fine M.Why caregivers of people with dementia and memory loss don't use services. International Journal of Geriatric Psychiatry.2005; 20 (6), 537-546. doi: 10.1002/gps.1322

20. Haley W. The family caregivers role in alzheimer disease. Neurology 1997; 48 (5): 25-29. PMID:9153157

21.Şahin HA. Alzheimer hastalığını klinik belirtileri ve seyri. Turkiye Klinikleri J Med Sci. 2009; 2(1): 31-35. 


\section{ISSN 2321-1091}

22.Reed C, Belger M, Dell'agnello G, et al. Caregiver Burden in Alzheimer's Disease: Differential Associations in AdultChild and Spousal Caregivers in the GERAS Observational Study. Dement Geriatr Cogn Dis Extra. 2014;19;4(1):51-64. doi: 10.1159/000358234.

23.Conde-Sala JL, Garre-Olmo J, Turró-Garriga O, Vilalta-Franch J, López-Pousa S. Differential features of burden between spouse and adult-child caregivers of patients with Alzheimer's disease: an exploratory comparative design. Int $\mathrm{J}$ Nurs Stud 2010; 47(10): 1262-1273. doi: 10.1016/j.ijnurstu.2010.03.001.

24.Mohamed S, Rosenheck R, Lyketsos CG, Schneider LS. Caregiver burden in Alzheimer disease: cross-sectional and longitudinal patient correlates. Am J Geriatr Psychiatry 2010; 18(10): 917-927. doi: 10.1097/JGP.0b013e3181d5745d.

\section{Table 1. Quality of Life Scale-Brd Of Caregil ers and control groups}

\begin{tabular}{ll|ll}
$\begin{array}{l}\text { Qualityof Life Scale- } \\
\text { Bref }\end{array}$ & Caregiver's group & Control group & P value8 \\
& Mean-Est & :Vkan
\end{tabular}

Subscales

Physical health

53.81d:19.46

7931L-19.99

0.000

Ps\}chological health

$56.47 \pm 13.03$

$7729^{4} .-2264$

0.000

Social relationship

52.72-i-21.37

S058\%1-1635

0.000

Environment

$56.60=15.83$

S4.27-1-13.42

0.000

*le Mana Whitney ti, $p<0.005$ 